\title{
Negociações comerciais em uma economia fechada: o Brasil e o comércio de serviços na Rodada Uruguai
}

\author{
Trade negotiations in a closed economy: Brazil and the \\ negotiations on trade in services in the Uruguay Round
}

http://dx.doi.org/10.1590/0034-7329201500108

RAPHAEL COUTINHO DA CUNHA*

Rev. Bras. Polít. Int. 58 (1): 142-163 [2015]

A diplomacia brasileira tem tradicionalmente adotado postura defensiva nas negociaçôes multilaterais sobre o comércio de serviços. $\mathrm{O}$ tema foi introduzido na agenda das negociaçóes comerciais amparadas pelo Acordo Geral de Tarifas e Comércio (GATT) em 1986, com o lançamento da Rodada Uruguai. Desde o princípio, o Brasil se opôs à iniciativa norte-americana e angariou o apoio de outros países em desenvolvimento em torno de sua posiçáo. A literatura é inequívoca ao caracterizar a posição brasileira como defensiva e obstrucionista nas discussóes relativas ao tema (Abreu 1997, 329; Abreu 2001, 92; Abreu 2007, 3-4, 148; Caldas 1998, 4-5; Mattoo 2004, 256; Mello 1992, 55-56; Preeg 1995, 194). Entre 1982 e 1986, durante o período de definição da agenda da rodada que estava por vir, o Brasil buscou obstruir a inclusão do tema de serviços na agenda negociadora. Ao perceber que não seria capaz de impedir sua inclusão, procurou convencer as demais partes contratantes do GATT a dissociar formalmente as negociaçóes de bens e serviços, de modo que não fosse possível haver concessóes cruzadas entre os temas. Dessa forma, supunha-se que conseguiria resistir às pressóes dos países demandantes e contrair menos compromissos de liberalização do setor de serviços ao fim da rodada.

Após a inclusão do tema na agenda e a separação formal das negociações de bens e serviços, os negociadores brasileiros se esforçaram para limitar ao mínimo possível suas ofertas em serviços. Ao fim das negociaçóes, o governo brasileiro logrou adotar um número restrito de compromissos e considerou-se satisfeito não apenas com o acordo-quadro resultante - o Acordo Geral sobre Comércio de Serviços (GATS) -, como também com o formato adotado para a inscrição

* Departamento de Ciências Políticas, Ohio State University, Columbus, Ohio, EUA (cunha.6@osu.edu). 
de compromissos - as listas positivas de compromissos específicos. Para o Brasil, esses resultados permitiam a manutenção de uma série de medidas restritivas ao comércio de serviços e davam ampla margem de manobra em rodadas futuras de liberalização.

Por que a diplomacia brasileira adotou posição tấo defensiva? São três as principais categorias explicativas comumente usadas para entender os determinantes domésticos da diplomacia econômica e da política comercial: interesses (Bouzas 2006; Marzagão 2008; Pinheiro e Almeida 1994; Carvalho 2001, 2003; Mancuso e Oliveira 2006; Oliveira e Pfeifer 2006; Veiga 2006; Farias s.d.), instituiçóes (Almeida 2005, 452-464; Cheibub 1985, 1989; Farias 2008, 2009, 2010) e ideias (Arbilla 1997; Castelan 2010; Faria 2003; Farias 2008; Pio 2001; Spektor 2010). Neste estudo, avalio o papel dessas variáveis na determinaçáo da posiçáo brasileira nas negociações de serviços da Rodada Uruguai.

O estudo de caso aqui apresentado descreve em detalhes a posição negociadora do país ao longo da rodada, identifica os interesses e preferências dos atores governamentais e não governamentais relevantes e reconstitui os mecanismos e instâncias de interação entre governo e setor privado. O estudo trata do setor de serviços em geral e de dois subsetores em particular: engenharia e construçáo e serviços financeiros. $\mathrm{O}$ trabalho empírico se baseia em documentação primária e em entrevistas com diplomatas brasileiros e com representantes do setor empresarial.

\section{O Brasil nas negociações de serviços da Rodada Uruguai: da obstrução aos compromissos mínimos}

Desde o começo da década de 1980, quando os Estados Unidos tomaram a iniciativa de propor uma nova rodada multilateral de negociaçóes comerciais no GATT que incluísse em sua agenda o tema do comércio de serviços, os negociadores brasileiros em Genebra consideravam que essa iniciativa continha "uma forte ameaça aos interesses comerciais e desenvolvimentistas dos países em desenvolvimento". ${ }^{1}$ Predominava entre os formuladores da estratégia brasileira a noção de que negociaçóes nas bases pretendidas pelos Estados Unidos seriam "ab initio, desfavoráveis ao Brasil". ${ }^{2}$ Também orientava a atuação dos diplomatas brasileiros a ideia de que o GATT era um "foro sabidamente desfavorável aos países em desenvolvimento e orientado por princípios do liberalismo comercial". ${ }^{3}$ Enfim, afirmava a Divisão de Política Comercial (DPC) do Itamaraty que "não

\footnotetext{
1 Telegrama 2159 de DELBRASGEN para Exteriores Bsb. Secreto. Abertura dos mercados dos países desenvolvidos. Negociaçóes comerciais. 15 de dezembro de 1983. PNB ONU GII 1983.03.00, Pasta I. $\mathrm{CPDOC/FGV.}$

2 Papel da Divisão de Política Comercial (DPC). GATT. Nova Rodada. Serviços. Posição Brasileira. Agosto de 1985. PNB ONU GII 1983.03.00, Pasta XI, Doc. 16. CPDOC/FGV.

3 Ibid.
} 
interessaria ao Brasil a participação em qualquer tipo de rodada de negociaçóes comerciais", sobretudo uma que incluísse os chamados "novos temas". ${ }^{4}$

Frente à tentativa formal norte-americana de incluir o tema de serviços na pauta de uma rodada multilateral, as instruçóes recebidas de Brasília pelo negociador na ocasião ordenavam "declarar, como princípio, que o GATT não contempla especificamente esta matéria, cuja amplitude é de tal ordem que poderá levar a interferências indébitas em questóes de competência exclusiva de cada Parte Contratante".

A Declaração Ministerial adotada em 1982 refletiu a conciliação de posiçóes entre os defensores e os opositores do tratamento do tema de serviços no âmbito do GATT (Croome 1998, 7-9). A declaração recomendou que os países realizassem estudos nacionais sobre o setor de serviços e trocassem informaçôes sobre o tema. Nâo havia reconhecimento de que o tema deveria ser tratado definitivamente no GATT. Ficaria adiada para 1984 a decisão sobre a inclusão do tema em eventual rodada. ${ }^{6}$

A noção de que não era do interesse brasileiro submeter-se a regras internacionais sobre o tema perpassa toda a correspondência trocada entre Brasília e a Missão Permanente do Brasil em Genebra. O negociador brasileiro em Genebra entendia como sendo de "grande interesse" para o país "preservar essa autonomia de decisão, que lhe [permitia] resolver unilateralmente, por legislação interna, o grau de abertura mais conveniente em cada setor de serviços ao comércio internacional ou a investimentos estrangeiros" ${ }^{7}$ A resistência ao tratamento do tema no âmbito do GATT atendia à "preocupação de evitar a extensão a serviços de regras aplicáveis ao comércio de mercadorias, tais como a da não discriminação entre produtos importados e produtos nacionais e a de recurso ao GATT como instância supranacional para solução de controvérsias". ${ }^{8}$

A partir dessa percepção de que negociações sobre serviços representariam ameaça aos interesses do país, a diplomacia brasileira entendia que deveria adotar uma "linha de ação que [visasse] [...] a neutralizar, esvaziar ou reorientar as iniciativas arroladas" "pelos países desenvolvidos. A estratégia advogada pela Divisão

\footnotetext{
4 Papel da Divisão de Política Comercial (DPC). Uma nova rodada de negociações comerciais - posição brasileira. Abril de 1985. PNB ONU GII 1983.03.00, Pasta VIII. CPDOC/FGV.

5 Despacho Telegráfico 1354 para DELBRASGEN. Reuniāo Ministerial do GATT. Novos temas. Entendimentos Brasil-EUA. Secreto-Urgentíssimo. 19 de novembro de 1982. CDO/MRE.

6 GATT. L/5424. Ministerial Declaration. 29 November 1982.

7 [Sem autor e data]. PNB ONU GII 1983.03.00, Pasta II, Doc. 24. Ref.: 1985-87. CPDOC/FGV. Ver também: [Sem autor e data]. PNB ONU GII 1983.03.00, Pasta II, Doc. 22. Ref.: 1985-87. CPDOC/FGV; "A Questão de Serviços no GATT”. Confidencial. [Sem autor]. 20 de agosto de 1985. PNB ONU GII 1983.03.00, Pasta XI, Doc. 3. CPDOC/FGV; Report to the CPs. Pré-condiçóes. [Sem autor e data]. PNB ONU GII 1983.03.00, Pasta III, Doc. 10. Ref.: 1983-87. CPDOC/FGV.

8 [Sem autor e data]. PNB ONU GII 1983.03.00, Pasta II, Doc. 22. Ref.: 1985-87. CPDOC/FGV.

9 Telegrama 2159 de DELBRASGEN para Exteriores Bsb, op. cit.
} 
de Política Comercial do MRE era assumidamente obstrucionista. ${ }^{10}$ As instruçóes recebidas pela Missão brasileira em Genebra orientavam a "explorar ao máximo quaisquer possibilidades dilatórias que porventura [existissem]" indicar que o Brasil deveria explorar "todas as possibilidades de retardamento do início das negociaçóes até o limite em que, ou se ameace uma ruptura do processo, ou o Brasil seja dele marginalizado ou, ainda, nossa atividade multilateral ameace causar sério conflito no plano bilateral com os EUA. ${ }^{12}$

A partir de certo momento, o negociador brasileiro passou a perceber que a manutenção de uma posição defensiva e obstrucionista não seria sustentável. Em seu entendimento, tornava-se "muito difícil prosseguirem os LDCs numa linha de simples procrastinação do cumprimento da etapa de troca de informaçóes". ${ }^{13}$ Isso porque parecia provável que cedo ou tarde "[aumentaria] o consenso entre os EUA e a CEE" e que "vários países em desenvolvimento poderiam vir romper a solidariedade até agora obtida com certo esforço". ${ }^{14}$ De fato, o trabalho de realização de estudos nacionais sobre serviços e troca de informaçóes entre os membros serviu para convencer alguns países de que seria interessante negociar o tema no GATT, aumentando progressivamente o apoio à iniciativa americana (Croome 1998, 11; Abreu 1997, 346).

A partir de 1984, portanto, começa-se a pensar em "moderar a linha obstrucionista ou dilatória”. ${ }^{15}$ Em vez da não-participação na negociação, passou-se a crer ser necessário "tentar influir ao máximo sobre a condução desse processo". ${ }^{16}$ Por outro lado, também se pensava que era do interesse brasileiro o fortalecimento do regime multilateral de comércio, pois o "bilateralismo [...] seria seguramente ainda mais contrário aos interesses nacionais", por "reduzir nossa capacidade de manobra e resistência”. ${ }^{17}$ A maneira encontrada para tentar resguardar a autonomia

10 Memorando do Chefe da Divisão de Política Comercial (DPC). Eventuais negociaçôes no GATT. Posição dos EUA. Repercussóes sobre os interesses brasileiros. Setembro de 1985. PNB ONU GII 1983.03.00, Pasta XII, Doc. 8. CPDOC/FGV.

11 Despacho Telegráfico 1495. GATT. 40a Sessão das Partes Contratantes. Serviços. Instruções. ConfidencialUrgentíssimo. 22 de novembro de 1984. PNB ONU GII 1983.03.00, Pasta VI. CPDOC/FGV. Ver também Despacho Telegráfico 1496. GATT. 40a Sessão das Partes Contratantes. Instruçôes. Agricultura, Salvaguardas, Contrafação, Alta Tecnologia e Serviços. Confidencial. 23 de novembro de 1984. PNB ONU GII 1983.03.00, Pasta VI. CPDOC/FGV.

12 Memorando do Chefe da Divisão de Política Comercial (DPC). Eventuais negociaçóes no GATT. Posição dos EUA. Repercussóes sobre os interesses brasileiros, op. cit.

13 Telegrama 1815 de DELBRASGEN para Exteriores. GATT. Sessão das Partes Contratantes. Grupo de Trabalho Sobre Serviços. Negociaçóes Sul-Norte. Secreto. 7 de novembro de 1984. PNB ONU GII 1983.03.00, Pasta VI. CPDOC/FGV.

14 Informação para o Senhor Ministro de Estado Indicado, Dr. Olavo Setúbal. Política comercial. Negociação no GATT. Confidencial. 12 de março de 1985. PNB ONU GII 1983.03.00, Pasta VIII, Doc. 15. CPDOC/FGV.

15 Telegrama 1815 de DELBRASGEN para Exteriores. GATT, op. cit.

16 Ibid.

17 Papel da Divisão de Política Comercial (DPC). GATT. Nova Rodada. Serviços. Posição Brasileira. Agosto de 1985, op. cit. 
regulatória do Estado brasileiro foi aceitar negociações sobre serviços, desde que conduzidas fora do quadro do GATT. ${ }^{18} \mathrm{O}$ Itamaraty passou a defender, então, a separação formal do processo negociador do comércio de serviços daquele do comércio de bens.

\section{A proposta de separação entre bens e serviços}

Veio do Brasil a proposta de separar formalmente as negociaçóes multilaterais de bens e serviços numa eventual nova rodada do GATT. A ideia seria elaborar um marco institucional para as negociações que permitisse a maior margem de manobra possível e que, assim, resultasse em limitados compromissos de liberalização dos setores de serviços da economia nacional. A intençáo era dissociar jurídica e politicamente as negociaçóes de serviços das de bens, de modo que elas transcorressem de forma independente, sem que houvesse a possibilidade de estabelecimento de concessôes cruzadas. ${ }^{19} \mathrm{Ou}$ seja, os países desenvolvidos não poderiam estabelecer um trade-off entre os interesses ofensivos brasileiro em bens e os interesses defensivos em serviços. Acreditava-se que, dessa forma, os países desenvolvidos teriam menos elementos de barganha para extrair concessóes do Brasil em serviços (Abreu 1997, 332).

A proposta brasileira de separação formal das negociações nas duas áreas foi anunciada aos demais membros pela primeira vez em reuniáo informal realizada em Estocolmo em junho de 1985 (Croome 1998, 17). Em 18 de junho de 1985, a delegaçáo norte-americana declarou que aceitava a proposta de negociaçóes separadas para bens e serviços. ${ }^{20} \mathrm{Em}$ julho de 1985, o Brasil formalizou às demais partes contratantes as condiçóes para a aceitação do lançamento de negociaçóes em serviços. ${ }^{21}$ Em agosto de 1985, já estava claro que o país não mais se oporia à inclusão do tema.

As tentativas de bloqueio das negociaçóes cessaram de vez em 1986, quando as partes contratantes do GATT chegaram a termo quanto ao lançamento de uma nova rodada multilateral de negociaçóes comerciais - a Rodada Uruguai. O Brasil e seus apoiadores haviam ficado cada vez mais isolados na tentativa de bloquear o lançamento de uma nova rodada com novos temas e já não tinham como impedir uma decisão sobre o lançamento da nova rodada (Croome 1998, 22).

18 [Sem autor e data]. PNB ONU GII 1983.03.00, Pasta III, Doc. 11. Ref.: 1983-87. CPDOC/FGV.

19 Telegrama 1043 de DELBRASGEN para Exteriores Bsb. GATT. Negociaçōes Comerciais. Avaliaçấo da Reunião de Estocolmo. Confidencial-Urgentíssimo. 18 de junho de 1985. PNB ONU GII 1983.03.00, Pasta IX. CPDOC/FGV. Ver também Despacho Telegráfico 712. GATT. Nova Rodada. Posiçấo Brasileira. SecretoUrgentíssimo. 23 de junho de 1985. PNB ONU GII 1983.03.00, Pasta IX. CPDOC/FGV.

20 Telegrama 1050 de DELBRASGEN para Exteriores Bsb. GATT. Negociaçôes Comerciais sobre Bens e Serviços. Secreto-Urgentíssimo. 19 de junho de 1985. PNB ONU GII 1983.03.00, Pasta IX. CPDOC/FGV.

21 GATT. C/W/479. Recent Developments in International Trade and Their Consequences for GATT, and Status of Implementation of the 1982 Ministerial Work Programme: Communication from Brazil. 18 July 1985. 


\section{Consultas internas às agências governamentais}

O Ministério das Relaçóes Exteriores realizou ampla consulta às demais agências do governo brasileiro com o objetivo de aprender sobre o setor de serviço nacional e sua regulamentaçáo e de discutir internamente a posiçáo a ser adotada pelo país nas negociaçóes multilaterais. Da documentação disponível, depreende-se que havia consenso no governo brasileiro como um todo quanto à falta de interesse na elaboração de disciplinas internacionais para o setor. Nas palavras do Itamaraty, "a posição brasileira [refletia] um amplo consenso interno contrário à inclusão de serviços numa nova rodada". ${ }^{22}$

Entre 1983 e 1984, o Itamaraty consultou vinte e um órgãos e empresas dos setores de bancos, seguros, transportes aéreo e marítimo, telecomunicaçóes, informática, engenharia e consultoria. Foram consultadas também algumas entidades de representação do empresariado e a Petrobrás. Em janeiro de 1984, poucos órgãos haviam respondido à consulta. ${ }^{23}$

Segundo relato do Itamaraty, era possível detectar "unanimidade" entre os respondentes sobre algumas posiçóes. Primeiro, a aplicação das regras do GATT ao setor de serviços contrariaria a legislação nacional e, até mesmo, princípios constitucionais. Não havia interesse na alteração da regulamentação vigente nos diversos setores. ${ }^{24} \mathrm{Em}$ termos de interesse exportador e acesso ao mercado de outros países, desconfiava-se da "efetiva abertura dos mercados dos países desenvolvidos aos serviços estrangeiros" e, no tocante ao mercado dos países em desenvolvimento, acreditava-se que "tal abertura favoreceria nossos concorrentes desenvolvidos". 25 A conclusão da consulta foi que "nenhum dos órgãos que responderam ao questionário demonstraram qualquer interesse em uma negociação internacional em matéria de serviços". ${ }^{26}$

Para a formulação de uma posição do governo brasileiro, o Itamaraty institucionalizou a discussão interna sobre as negociações de serviços por meio da criação do Grupo Interministerial de Serviços (GIS), sob sua própria coordenação. ${ }^{27}$ Em 1986, o GIS aprovou por unanimidade documento de posição que considerava "contrária aos interesses nacionais uma negociação no GATT sobre serviços"28. Das discussóes no GIS, o Itamaraty concluiu que "em todos aqueles setores em que

22 Informação para o Senhor Presidente da República. GATT. Reunião Ministerial das Partes Contratantes. Punta del Este: Instruções à Delegação Brasileira. Setembro de 1986. PNB ONU GII 1983.03.00, Pasta XVIII, Doc. 33. CPDOC/FGV.

23 Despacho Telegráfico 015 62350. GATT. Serviços. Reunião Informal. Confidencial-Urgente. 6 de janeiro de 1984. PNB ONU GII 1983.03.00, Pasta IV. CPDOC/FGV.

24 Ibid.

25 Ibid.

26 Ibid.

27 [Sem autor e data]. PNB ONU GII 1983.03.00, Pasta II, Doc. 22. Ref.: 1985-87. CPDOC/FGV.

28 Informação para o Senhor Presidente da República. GATT. Reuniâo Ministerial das Partes Contratantes. Punta del Este: Instruçôes à Delegação Brasileira, op. cit. 
há um relacionamento mais intenso com o exterior e que, portanto, constituiriam o cerne da discussão no GATT, há unanimidade de pontos de vista contrários a uma negociação". ${ }^{29}$ As manifestaçóes dos diversos órgãos participantes do GIS indicavam que "uma negociação sobre serviços no GATT tendente à liberalização do setor não atende aos interesses brasileiros e pode apresentar sérios riscos para a economia nacional". ${ }^{30} \mathrm{~A}$ justificativa para tal posição era que "o interesse central dos referidos setores é a defesa do mercado brasileiro para as empresas nacionais" 31 e que a legislação nacional sobre o tema deveria ser preservada, pois tinha "como um de seus objetivos centrais favorecer o fornecedor nacional". ${ }^{32}$

Não há registro de divergências interburocráticas relevantes sobre o tema. Há menção de que as autoridades brasileiras da área econômico-financeira eram, inicialmente, mais sensíveis à iniciativa norte-americana de inclusão do tema do comércio de serviços na agenda. A razão dessa sensibilidade encontrava-se na primeira renegociação da dívida externa brasileira. O Ministro do Planejamento, Delfim Netto, e o da Fazenda, Ernane Galvêas, argumentavam em 1985 ser "indispensável apoiar em Genebra as posiçôes norte-americanas no GATT para garantir a obtenção pelo Brasil de bridge-loans do Tesouro dos EUA". ${ }^{33}$ De fato, os Estados Unidos haviam tentado utilizar a seu favor a vulnerabilidade brasileira decorrente da crise financeira internacional deflagrada em 1982, exercendo pressão com vistas à diminuição da resistência aos novos temas (Abreu 1996, 208). A posição defensiva, porém, prevaleceu; em 1986 o Ministério da Fazenda referendaria a posição conjunta do GIS contrária à negociação de serviços.

\section{As negociações da Rodada Uruguai}

As negociaçóes durante a Rodada Uruguai se dividiram em duas tarefas: a elaboraçáo de um acordo geral com princípios e regras para disciplinar o comércio de serviços e o estabelecimento de compromissos de liberalização específicos para os diversos subsetores de serviços. Inicialmente, o Brasil definiu sua estratégia negociadora como sendo de "prolongar a discussão prévia à negociação" e "manter a negociação ao nível de um quadro jurídico geral sobre comércio de serviços evitando que ela [passasse] à fase de acordos sobre setores específicos". ${ }^{34}$ Ademais, as

29 Despacho Telegráfico s/n para DELBRASGEN. GATT. Nova rodada. Declaração ministerial. 11 de julho de 1986. CDO/MRE.

30 Ibid.

31 Memorando do Chefe da Divisão de Política Comercial (DPC). Eventuais negociaçôes no GATT. Posição dos EUA. Repercussōes sobre os interesses brasileiros, op. cit.

32 Ibid. Ver também Despacho Telegráfico 1051. GATT. Grupo Interministerial sobre Serviços. Conclusôes e Recomendaçōes. 3 de setembro de 1986. CDO/MRE.

33 A Questão de Serviços no GATT. Reservado. [Sem autor]. Dezembro de 1985. PNB ONU GII 1983.03.00, Pasta XIII, Doc. 26. CPDOC/FGV.

34 Papel da Divisão de Política Comercial (DPC). O Brasil e a Rodada Uruguai. 19 de novembro de 1987. PNB ONU GII 1983.03.00, Pasta XXVI, Doc. 25. CPDOC/FGV. 
instruçóes para o posicionamento brasileiro durante a rodada indicavam que o Brasil deveria buscar "reduzir ao mínimo o escopo das negociações". ${ }^{35}$ Brasília também orientava seu delegado a evitar "ofertas naqueles setores onde se [configurasse] uma incompatibilidade entre as regras multilaterais e a legislação interna ou onde [pudessem] ser afetadas nossas possibilidades de desenvolvimento". ${ }^{36}$

Nessa mesma linha, o país defendia, no Grupo Negociador de Serviços (GNS), a visão de que o "objetivo da negociação não [era] a liberalização, mas sim o crescimento e o desenvolvimento". ${ }^{37}$ Brasil, Egito e Índia chegaram a argumentar que o mandato do GNS não ia além da negociação de um acordo geral com regras e princípios; a negociação de compromissos específicos deveria ser levada a cabo após a conclusão da rodada (Croome 1998, 210).

Abreu $(2007,167)$ mostra que, entre 1986 e 1988, em decorrência da reavaliação do modelo de economia fechada iniciada no governo Sarney, procede-se a uma "substituição gradual do comprometimento anterior quanto ao bloqueio de negociaçôes sobre novos temas por um papel mais ativo em relação à agricultura". A "consolidação da transiçáo brasileira rumo a uma pauta ativa" nas negociaçóes ocorreu em fins de 1990, sob o movimento de abertura comercial do governo Collor (Abreu 1996, 215). Não obstante tal reorientação, o comportamento brasileiro nas negociações de serviços, em particular, não parece ter sofrido impacto relevante das redefiniçóes sofridas pela política comercial do país. No governo Collor, houve um ensaio de mudança de posição nas negociaçóes de serviços. O Itamaraty chegou a receber pressóes de alguns órgáos do governo para adotar uma postura menos defensiva; mas, na prática, a posição brasileira não foi afetada. ${ }^{38}$ De fato, o Brasil seguiu buscando regras e compromissos que contemplassem a maior margem de manobra interna para políticas governamentais.

As discussôes sobre um marco normativo com regras e princípios teve momentos contenciosos. Nas últimas semanas antes da reunião ministerial de Bruxelas em 1990, os Estados Unidos endureceram sua posição. Não queriam uma cláusula de nação-mais-favorecida (NMF) geral e incondicional, mas uma condicionada à barganha de compromissos específicos (Croome 1988, 214). Os EUA mantinham tratados bilaterais que estabeleciam relaçóes preferenciais com determinados países em alguns setores de serviços e não queriam estender essas preferências aos demais países, sem receber em troca ganhos importantes de acesso a mercado.

35 Memorando do Chefe da Divisão de Política Comercial (DPC). Eventuais negociações no GATT. Posição dos EUA. Repercussões sobre os interesses brasileiros, op. cit.

36 Fac-símile 206 de DEC para Brasemb Washington. 7 de novembro de 1991. MMM mefp 1991.06.14, Pasta Única, Doc. 2A. CPDOC/FGV.

37 Papel da Divisão de Política Comercial (DPC). O Brasil e a Rodada Uruguai, op. cit. Ver também Croome $(1998,107)$.

38 Entrevista ao autor do Ministro Luis Antonio Balduino. 
Havia oposição quase consensual entre os demais membros à ideia americana de uma cláusula NMF condicionada a barganhas bilaterais específicas (Croome 1998, 215). O negociador brasileiro tinha instruçóes para defender uma cláusula de não discriminação "automática e incondicional"39, com o menor número possível de derrogaçóes. ${ }^{40}$ Havia a percepçáo de que "para um país com pequena parcela do comércio internacional, o fator singular mais importante das regras multilaterais [era] uma cláusula NMF forte e incondicional". ${ }^{41}$ A opção tática brasileira, nesse caso, seria limitar sua lista de derrogaçóes ao mínimo, de modo que o país pudesse concentrar toda sua argumentação na defesa de disciplinas rígidas para as derrogações.

A solução encontrada pelo presidente do GNS foi permitir que os países explicitassem, em uma lista de derrogaçóes à cláusula NMF, as medidas discriminatórias que mantinham em tratados bilaterais. Estas medidas teriam isençáo de tratamento NMF por um período de 10 anos, depois do qual qualquer extensão deveria ser negociada e compensada (Croome 1998, 275).

Quanto ao modelo de adoção de compromissos específicos, havia duas possibilidades na mesa. Uma era o modelo de listas positivas: os países se comprometeriam com a liberalizaçáo daqueles setores que fossem explicitamente incluídos em sua lista. A outra era o modelo de listas negativas: os países se comprometeriam com a liberalização de todos os setores que não fossem incluídos expressamente em sua lista. Estados Unidos e Comunidades Europeias defendiam uma abordagem de listas negativas, porque ela ampliaria o escopo de aplicação do acordo. Países em desenvolvimento preferiam uma abordagem de listas positivas, que facilitava um menor número de compromissos (Croome 1998, 210). O delegado brasileiro possuía instruções para "defender a elaboração de listas positivas de serviços a serem abrangidos pelo eventual Acordo, em contraposição às propostas alternativas de outros países". O modelo de listas positivas era mais desejável por proporcionar maior margem de manobra ao país na elaboração de sua oferta. ${ }^{42}$

Em relação à oferta inicial brasileira de compromissos específicos, preocupava o Itamaraty a pouca flexibilidade de que dispunha para elaborar sua lista de oferta. De acordo com as instruçóes de Brasília, a existência de alguma margem de manobra para a expansão da lista de oferta brasileira tornava-se "tanto mais necessária quanto náo [poderia] vir a contemplar alguns dos setores essenciais nas negociaçôes" ${ }^{33}$ - setores esses visados pelos demandeurs, como telecomunicaçóes

39 Telegrama 1590 de Delegação em Genebra para Exteriores. Rodada Uruguai. Serviços. Participaçáo brasileira. Confidencial-Urgente. 13 de dezembro de 1990. CDO/MRE.

40 Fac-símile 206 de DEC para Brasemb Washington. 7 de novembro de 1991, op. cit.

41 Telegrama 1492 de Delegação em Genebra para Exteriores. Rodada Uruguai. Serviços, Nação Mais Favorecida. Secreto. 21 de outubro de 1991. CDO/MRE.

42 Despacho Telegráfico 619. Rodada Uruguai. Serviços. Reunião do GNS em junho de 1990. Subsídios. Confidencial-Urgente. 8 de junho de 1990. CDO/MRE.

43 Despacho Telegráfico 091. GATT. Rodada Uruguai. GN sobre serviços. Lista de oferta brasileira. ConfidencialUrgentíssimo. 5 de fevereiro de 1991. CDO/MRE. 
e serviços bancários. Não obstante, o delegado brasileiro em Genebra avaliou positivamente os resultados parciais da negociação, afirmando que "nos temas de maior impacto potencial sobre o Brasil, [podia-se] dizer que [haveria] suficiente espaço de manobra para a preservação de nossos interesses". ${ }^{44}$

Quanto ao setor bancário, restringia a margem de atuação do negociador brasileiro o fato de o Congresso Nacional estar examinando projeto de lei complementar que regulamentava o dispositivo constitucional sobre o sistema financeiro nacional. O artigo 192 da Constituição de 1988 estipulava que o sistema financeiro nacional seria regulado por meio de lei complementar; ao mesmo tempo, o artigo 52 do Ato das Disposiçóes Constitucionais Transitórias vedava a instalação de instituiçôes estrangeiras no país até que o artigo 192 fosse regulamentado. Um representante do Banco Central informou ao MRE que isso impedia qualquer movimento em termos de negociação internacional que "prejulgasse os resultados da decisão legislativa". ${ }^{45} \mathrm{~A}$ perspectiva do BACEN era a de que não restava alternativa, senão "esperar a reforma constitucional de 1993 (ou 1992), tentar eliminar aquele dispositivo e só depois preocupar-se com a regulamentação da matéria”. ${ }^{46}$ Como resultado, a oferta brasileira em serviços não incluía o setor de serviços financeiros.

De fato, serviços financeiros foi o setor que encontrou as maiores resistências por parte de múltiplos países. Por essa razão, Canadá, Japão, Suécia e Suíça introduziram uma proposta de negociaçáo em dois trilhos para serviços financeiros segundo a qual os países que estivessem mais dispostos a aprofundar seus compromissos poderiam fazê-lo separadamente, sem a obrigatoriedade de participação de todos os membros nos resultados. O objetivo era atingir um maior grau de liberalizaçáo para o setor entre esses países do que se conseguiria nas negociaçóes gerais (Croome 1998, 243, 273). No fim, a proposta dos dois trilhos prevaleceu. Enquanto a maioria dos países optou por adotar compromissos em serviços financeiros de acordo com as regras previstas no acordo geral, os países da OCDE aderiram ao "Entendimento Relativo aos Compromissos em Matéria de Serviços Financeiros" - instrumento plurilateral de adesấo facultativa que estabelecia uma fórmula de liberalização mais profunda (Marconini 2003, 87-88).

As instruçôes de Brasília relativas às negociaçôes de serviços para o esforço negociador final da Rodada Uruguai indicavam que, em termos da oferta de compromissos específicos, deveria ser "esclarecido aos demais países que o espírito da oferta brasileira, [naquele momento, era] de manutenção do 'status quo', não havendo possibilidade imediata de se negociar a revogação de leis, decretos e regulamentos". ${ }^{47}$

44 Telegrama 1833 de Delegação em Genebra para Exteriores. GATT. Rodada Uruguai. “Draft Final Act”. IX-Serviços. Confidencial-Urgentíssimo. 24 de dezembro de 1991. MMM mefp 1991.06.14, Pasta Única. CPDOC/FGV.

45 Despacho Telegráfico 091, op. cit.

46 Ibid.

47 Despacho Telegráfico 1213. GATT. Rodada Uruguai. Serviços. Instruçôes. Confidencial. 25 de outubro de 1991. CDO/MRE. 
Segundo o negociador brasileiro em Genebra, "a delegação norte-americana [havia-se mostrado] satisfeita com a oferta inicial brasileira" ${ }^{48}$ Em reunião com o Tesouro norte-americano para discutir a oferta brasileira, o negociador brasileiro indicou "não ser nossa intenção ampliar a oferta e reiterou nossas dificuldades constitucionais em relação ao setor financeiro". O representante norte-americano chegou a comentar, segundo relato da Delegaçáo do Brasil em Genebra, que "a oferta brasileira foi considerada uma das mais interessantes quando tabulada". ${ }^{49}$

Além do esforço de elaboração da oferta, a diplomacia brasileira ainda cogitou identificar interesses exportadores, com o intuito de elaborar pedidos de abertura de determinados setores para os demais países da negociação. De Genebra, recomendava-se a "conduçáo de ampla consulta aos setores interessados com o objetivo de recensear interesse exportador brasileiro em serviços e possíveis barreiras encontradas à expansão das exportaçóes brasileiras nos diversos setores". ${ }^{50}$ Acreditava-se que, entre os setores interessados, poderiam estar os de serviços audiovisuais, serviços profissionais, turismo e, sobretudo, engenharia e construção. ${ }^{51}$ Porém, acabou-se por decidir que o país não apresentaria lista de demandas de liberalização às suas contrapartes negociadoras. ${ }^{52}$

A despeito das mençôes quanto à boa aceitaçáo da oferta brasileira por parte dos Estados Unidos, há registros de que os demandeurs náo estavam tão satisfeitos com o que estava sendo ofertado pelo Brasil. O país passou a estar em evidência a partir do momento em que a maioria dos países em desenvolvimento parecia "ampliar muito suas ofertas em serviços, o que caracterizaria [aos olhos dos nossos interlocutores] um certo imobilismo da parte do Brasil". ${ }^{53}$ As contrapartes na negociação manifestavam interesse sobretudo nos setores ausentes da oferta brasileira - serviços financeiros, telecomunicaçóes e informática. ${ }^{54} \mathrm{O}$ negociador brasileiro em Genebra à época, Celso Amorim, informou que esses setores "em princípio não estariam à venda" ${ }^{55}$ Os setores não eram inegociáveis, porém. Se fosse proposto um "preço suficientemente atraente" específicos brasileiros na área de bens -, o país poderia considerar a realização de compromissos nos setores mencionados.

48 Telegrama 200 de Delegação em Genebra para Exteriores. Rodada Uruguai. Serviços. Compromissos iniciais. Consulta com os EUA. Confidencial-Urgente. 20 de fevereiro de 1991. CDO/MRE.

49 Telegrama 1767 de Delegação em Genebra para Exteriores. Rodada Uruguai. Serviços Financeiros. Posição do Tesouro dos EUA. Confidencial. 17 de dezembro de 1991. MMM mefp 1991.06.14, Pasta Única. CPDOC/FGV.

50 Telegrama 049 de Delegação em Genebra para Exteriores. Rodada Uruguai. Serviços. Compromissos iniciais. Confidencial-Urgente. 17 de janeiro de 1991. CDO/MRE.

51 Ibid.

52 Despacho telegráfico 091, op. cit.

53 Telegrama 2042 de DELBRASGEN para Exteriores. GATT. Rodada Uruguai. Mercosul. Serviços. Secreto.

22 de dezembro de 1992. CDO/MRE.

54 Ibid.

55 Ibid.

56 Ibid. 
A posição brasileira nos momentos finais da negociação enfraqueceu-se porque os delegados dos países demandantes estavam "muito bem informados sobre iniciativas recentes da parte do governo brasileiro no sentido da liberalizaçáo ou desregulamentação de algumas importantes atividades de serviços" ${ }^{57} \mathrm{Na}$ visão deles, "havia cada vez menos razóes para o Brasil não ampliar sua oferta em setores importantes", como telecomunicaçôes e informática. ${ }^{58}$ Contribuiu, ademais, para o enfraquecimento da posiçáo brasileira a percepção norte-americana de que “o Brasil parecia 'isolado' no contexto do Mercosul, pois as ofertas da Argentina, Uruguai e Paraguai estavam mais condizentes com os pedidos norte-americanos". 59 Isso porque setores importantes eram incluídos com restriçóes na oferta brasileira, como engenharia e seguros, e outros estavam ausentes, como bancos, valores mobiliários e informática. O setor de serviços financeiros em particular era alvo de demandas dos principais parceiros na rodada. ${ }^{60}$

\section{Os compromissos assumidos}

Diversos indicadores quantitativos que buscam mensurar o nível de liberalização dos compromissos assumidos pelos países em negociaçóes multilaterais de serviços foram elaborados (e.g., Barth et al. 2006; Hoekman 1995; Marconini 2003; Mattoo 1999; Oliveira Júnior 2000). Alguns procuram medir o nível geral de abertura dos compromissos assumidos, enquanto outros sáo setoriais. Dos onze grandes setores de serviços negociáveis ao fim da Rodada Uruguai, o Brasil incluiu apenas sete em sua Lista de Compromissos Específicos. Para nenhum desses setores, no entanto, o Brasil incluiu todos os subsetores passíveis de serem negociados. Do total de 54 subsetores de serviços, o Brasil incluiu compromissos em apenas 17 (Marconini 2003, 237-238). Ademais, em relação a todos os compromissos possíveis de se assumir, o Brasil fez compromissos sem restriçôes em apenas 3\% do total (Marconini 2003, 313).

Quando comparado a países desenvolvidos e em desenvolvimento de porte semelhante, o Brasil adotou poucos compromissos ao fim da Rodada Uruguai. Em número absoluto de compromissos assumidos, o país não se diferenciou muito de outros países em desenvolvimento, à exceção de Argentina e África do Sul, que assumiram quantidade atipicamente alta de compromissos (Bouzas e Soltz 2005). No entanto, em termos do número de compromissos assumidos sem restriçóes e da proporção destes em relação ao número total de compromissos assumidos, o Brasil apresentou índices mais baixos de abertura, tanto para acesso a mercados quanto para tratamento nacional (Hoekman 1995).

57 Telegrama 966 de DELBRASGEN para Exteriores. Rodada Uruguai. Serviços. Consultas bilaterais com EUA e CEE. Secreto. 19 de junho de 1992. CDO/MRE.

58 Ibid.

59 Ibid.

60 Despacho Telegráfico s/n. GATT. Rodada Uruguai. Serviços. Reunião do Grupo Interministerial de Serviços. Confidencial. 7 de julho de 1992. CDO/MRE. 
$\mathrm{Na}$ comparação com países do Mercosul e da OCDE, a baixa disposição brasileira de assumir compromissos se mantém. O país se comprometeu menos que Argentina, Uruguai, Paraguai e os países da OCDE em termos de compromissos sem restriçóes proporcionalmente ao total de compromissos assumidos. Quanto ao número absoluto de compromissos assumidos sem restriçóes, a lista brasileira só foi menos restritiva que a paraguaia (Marconini 2003).

Por fim, em termos setoriais, focando engenharia e construção e serviços financeiros, os compromissos brasileiros também aparecem no rol dos mais restritivos. Com a exceção da ausência de compromissos chilenos para o setor de construçáo, o Brasil apresentou abertura setorial abaixo da média dos países latino-americanos e dos membros da OCDE, bem como de Argentina e Chile (Bouzas e Soltz 2005).

\section{As percepções da diplomacia sobre o setor nacional de serviços}

Para o negociador brasileiro em Genebra, a preservação da autonomia nacional de decisão no que respeita às barreiras nacionais ao comércio de serviços era importante em dois casos: "em áreas de serviços onde a capacitação nacional [era] ainda incipiente" ou em áreas que "são de grande valor estratégico para a economia nacional como um todo". ${ }^{61}$ Encaixavam-se nesses casos notadamente os setores de "bancos, seguros, engenharia e informática". ${ }^{62}$ No caso dos dois setores aqui tratados (engenharia e construçáo e serviços financeiros), a vontade de manter a "autonomia de decisáo nacional" era embasada numa combinaçáo dos dois argumentos. Por um lado, acreditava-se que, embora os dois setores já fossem bem desenvolvidos no país, "a indústria nacional de serviços nessas áreas não [teria] condiçóes de enfrentar a concorrência estrangeira, em regime de livre competição, nem sequer no mercado interno". ${ }^{33}$ Por outro lado, reiterava-se a noção de que ambos os setores eram estratégicos por suas implicaçóes sistêmicas para a economia nacional.

Em relação ao setor de engenharia, havia certa percepçáo de interesses ofensivos no governo brasileiro. Reconhecia-se uma "maior agressividade das empresas dos países em desenvolvimento". ${ }^{64}$ Além disso, entendia-se que as empresas brasileiras de construção e engenharia possuíam alguma vantagem competitiva em determinados mercados, de modo que estariam elas adaptadas às condiçôes socioeconômicas do país importador. Em suma, pensava-se que "o país já [havia desenvolvido] uma razoável competência, sobretudo nas áreas de execução de obras civis e de montagens industriais". ${ }^{65}$

61 [Sem autor e data]. PNB ONU GII 1983.03.00, Pasta II, Doc. 24. Ref.: 1985-87. CPDOC/FGV.

62 Informação sobre a Reuniáo Ministerial das Partes Contratantes do GATT, em Punta del Este. [Sem autor]. 2 de setembro de 1986. PNB ONU GII 1983.03.00, Pasta XVIII, Doc. 34. CPDOC/FGV.

63 Ibid.

64 GATT x Exportação de serviços. [Sem autor e data]. PNB ONU GII 1983.03.00, Pasta II, Doc. 13. Ref.: 1983-87. CPDOC/FGV.

65 [Sem autor e data]. PNB ONU GII 1983.03.00, Pasta II, Doc. 24. Ref.: 1985-87. CPDOC/FGV. 
Porém, insistia-se na ideia de que a "preservação do mercado interno para a engenharia nacional [era] condição essencial para que [ela pudesse] se consolidar e partir para o mercado externo" ${ }^{66}$ As posiçôes da diplomacia brasileira em relação ao setor de construção e engenharia eram também embasadas pela percepção de que o setor possuía "caráter estratégico", pois constituía "atividade-meio para o exercício de grande número de atividades finais em quase todos os campos de ação econômica". ${ }^{67}$

Acreditava-se, ademais, que, no setor de serviços financeiros, especialmente no setor bancário, já existia "forte capacitação brasileira, em perfeitas condiçóes de atendimento do mercado". ${ }^{68}$ A expressão "forte capacitação", no entanto, é ambígua, pois entendia-se que, ao mesmo tempo em que o setor era capaz de atender "em perfeitas condições" o mercado interno, o negociador brasileiro não estava convencido de que os bancos brasileiros estavam em condiçóes de concorrer com as instituiçốes financeiras estrangeiras. A alegação era que a "abertura ao capital estrangeiro não representaria necessariamente uma contribuição significativa em termos de aporte de capital ou de tecnologia”. Porém, os motivos mais importantes para a resistência à negociação do setor eram que a entrada de bancos estrangeiros no mercado nacional "poderia criar problemas ao manejo da política monetária e até ensejar condições competitivas desfavoráveis para o sistema bancário brasileiro". ${ }^{69}$

A diplomacia brasileira, como se pode notar a partir da documentaçáo, acreditava que não apenas no mercado interno teriam as empresas brasileiras dificuldades para competir com as estrangeiras. Em carta ao Secretário de Estado dos Estados Unidos, George Shultz, o então Ministro das Relaçôes Exteriores, Ramiro Saraiva Guerreiro, alertava que a aplicação dos "princípios livre-cambistas ortodoxos do GATT" ao comércio internacional de serviços afetaria seriamente "nossos incipientes índices de exportação de certos tipos de serviços - que se dirigem predominantemente para outros países em desenvolvimento". ${ }^{70}$

\title{
Ideias e conceitos dos negociadores brasileiros
}

Além das percepçóes dos atores governamentais sobre o setor nacional de serviços, é interessante também identificar as ideias e conceitos sobre o comércio internacional e sua relação com o desenvolvimento que orientavam a atuação dos negociadores e decisores brasileiros à época. Algumas dessas ideias podem ser extraídas da documentação diplomática disponível. No que tange às relaçóes comerciais internacionais, acreditava-se que "a 'liberaçáo do comércio' como

\author{
66 Ibid. \\ 67 Ibid. \\ 68 Ibid. \\ 69 Ibid. \\ 70 Carta do Ministro Guerreiro ao Secretário de Estado Schultz. 10 de novembro de 1982. PNB ONU GII \\ 1983.03.00, Pasta Anexos, Doc. A4. CPDOC/FGV.
}


doutrina de comércio internacional [era] um argumento implicitamente falacioso, visto que os próprios países industrializados [eram à época] os mais protecionistas". ${ }^{71}$ As discrepâncias na distribuição de capacidades econômicas entre os países também causavam descrença no negociador brasileiro quanto às vantagens oriundas do livre intercâmbio. Nessa linha de pensamento, não se poderia falar em livre comércio, "sem incentivos e proteçóes específicas, quando os concorrentes são desiguais em tecnologia, capital e lobby". ${ }^{72}$

Ademais, quanto ao papel do livre comércio no desenvolvimento econômico de uma nação, considerava-se que "nenhum país cria e desenvolve tecnologia sem haver uma fase inicial de incentivos e proteção". Na ausência desses incentivos e proteção, o Brasil não teria "criado e desenvolvido grandes empresas, a nível internacional, gerando riqueza para a economia". ${ }^{73} \mathrm{O}$ delegado brasileiro, em reunião de trabalho sobre serviços no GATT, manifestou que o país precisava desenvolver "indigenous creativity and apply suitable technology to attain its development objectives". O entendimento do delegado brasileiro era que "Brazil had learned from history: developed countries had, in the past, taken similar views". ${ }^{74}$ Em suma, as ideias dos formuladores da posição negociadora brasileira associavam desenvolvimento e crescimento econômico a um mercado doméstico protegido da concorrência estrangeira.

A documentação disponível, portanto, sugere que as ideias compartilhadas pelos diplomatas brasileiros atuantes nas negociaçóes sobre serviços constituem uma das principais variáveis explicativas da posição adotada pelo país em relação ao tema.

\section{As preferências do setor privado}

Os setores mais visados pelos Estados Unidos nas negociaçóes da Rodada Uruguai eram os de informática, bancos, engenharia e construção. O entendimento do Itamaraty era que os representantes dos setores envolvidos rejeitavam qualquer negociação que envolvesse liberalização do mercado brasileiro. ${ }^{75}$

De modo geral, o setor privado brasileiro, na época das negociaçóes da Rodada Uruguai, temia que os compromissos assumidos multilateralmente pelo país resultassem em maior concorrência no mercado interno. Mesmo para o setor de engenharia e construção, a proteção do mercado interno era prioritária em relação aos interesses exportadores. ${ }^{76}$

71 GATT x Exportação de serviços. [Sem autor e data], op. cit.

72 Ibid.

73 Ibid.

74 GATT. MDF/33. Services. Minutes of the meeting held on 12-13 May 1986. 23 June 1986.

75 Papel da Divisão de Política Comercial (DPC). O Brasil e o GATT. Abril de 1985. PNB ONU GII 1983.03.00, Pasta VIII. CPDOC/FGV.

76 Entrevista ao autor do Embaixador José Alfredo Graça Lima. 
Em termos de interesses ofensivos nas negociaçóes, os setores politicamente mais ativos eram os relacionados a serviços profissionais (como serviços jurídicos e outros serviços caracterizados por mão-de-obra especializada). Esses setores encontravam barreiras significativas de acesso nos mercados dos países desenvolvidos. ${ }^{77}$

Havia pouco interesse do empresariado pelas negociaçóes. De modo geral, o setor privado não vislumbrava impactos imediatos relevantes advindos das negociações. Entre os atores privados, houve maior atuação por parte da Ordem dos Advogados do Brasil (OAB) e da Odebrecht - empresa de construçấo e engenharia -, que chegaram a enviar representantes para reunióes em Genebra. Porém, os contatos eram, em geral, escassos. ${ }^{78}$

Não há referências específicas, na documentação e nas entrevistas realizadas, de atuação significativa de representantes do setor financeiro nacional junto ao governo brasileiro, de modo que não foi possível obter informaçóes precisas sobre suas preferências a respeito das negociações. O setor de engenharia e construção é tratado a seguir.

\section{Preferências do setor de engenharia e construção}

Em 1983 e 1984, o Itamaraty consultou, entre outros, a Associação Brasileira de Consultores de Engenharia (ABCE). Da comunicação diplomática, subentendese que a $\mathrm{ABCE}$ também fazia parte do conjunto de opiniôes unânimes em torno da não aplicação das regras do GATT ao setor de serviços. Parece particularmente aplicável ao setor de engenharia brasileiro a referência ao "desinteresse por uma abertura dos mercados dos países em desenvolvimento importadores de serviços do Brasil, pois se [considerava] que tal abertura favoreceria nossos concorrentes desenvolvidos". ${ }^{79}$

A agenda principal do setor privado brasileiro de construção e engenharia, contudo, passava ao largo das negociaçóes comerciais multilaterais do GATT. Seus principais interesses diziam respeito a instrumentos de promoção comercial e redução de custos e barreiras domésticas à sua competitividade externa; ou seja, sua agenda era de política doméstica e não de política externa.

No que tange às preferências relacionadas às negociaçôes em curso, em entrevista anônima ao autor, um representante do setor privado de engenharia e construção que, à época da Rodada Uruguai, representava uma entidade do setor junto ao governo, confirmou a informação contida na documentação diplomática de que, naquele momento, o setor não tinha interesse na abertura do mercado brasileiro às empresas estrangeiras, sobretudo porque não se tinha ideia clara

77 Ibid.

78 Entrevista ao autor do Ministro Luis Antonio Balduino.

79 Despacho Telegráfico 015 62350, op. cit. 
sobre o impacto de uma eventual abertura. Segundo esse representante, houve manifestação das preferências do empresariado ao governo em algumas ocasióes; porém, em decorrência da falta de percepção sobre as implicaçôes imediatas da negociação, sua atuação ainda era muito incipiente.

\section{A interação entre Estado e atores não governamentais}

Quais foram os canais de comunicação estabelecidos entre governo e setor privado e como eles foram utilizados? Na documentação disponível, é possível observar alguns dos episódios em que o governo brasileiro recebeu manifestaçóes do empresariado. Já em 1982, o Ministro das Relaçôes Exteriores escrevia ao Secretário de Estado norte-americano que "o governo brasileiro [estava recebendo] de empresas brasileiras numerosas expressóes de preocupação quanto aos riscos de uma extrapolação do GATT à área de serviços, expressóes a que, naturalmente, não [podia] ficar indiferente". 80

Representantes do setor privado estavam presentes na Reunião Ministerial do GATT de 1982. Entre as entidades credenciadas junto à delegação brasileira, estavam a Confederação Nacional do Comércio, a Associação dos Exportadores Brasileiros e a Federação das Indústrias do Estado de São Paulo. ${ }^{81}$

Entre 1983 e 1984, o Itamaraty realizou consulta a uma série de órgãos governamentais setoriais e também incluiu algumas poucas entidades representativas do setor privado. Consta que apenas a Associação Brasileira de Consultores de Engenharia (ABCE) respondeu à consulta em um primeiro momento. ${ }^{82}$ Segundo relato do MRE, as respostas recebidas - entre elas, supostamente, a da ABCE - eram unânimes em condenar a negociação do tema de serviços no âmbito do GATT. Esse levantamento preliminar sobre o setor de serviços brasileiros confirmou "a rejeição por parte dos setores envolvidos de qualquer negociação que envolvesse liberalização do mercado brasileiro". ${ }^{83}$ Portanto, informava o Itamaraty ao Presidente da República que "a posição governamental [estava sendo] fortemente respaldada por todos os setores produtivos nacionais, em especial os mais diretamente envolvidos na área de serviços, os quais, através de suas federaçóes e associaçóes de classe, têm se manifestado, sem discrepâncias, contra negociaçôes sobre serviços" ${ }^{84}$

Um documento datado de dezembro de 1986 relata um seminário informal sobre "o setor de serviços e o GATT" ${ }^{85}$ Entre os expositores do seminário, estavam

80 Carta do Ministro Guerreiro ao Secretário de Estado Schultz. 10 de novembro de 1982, op. cit.

81 Despacho Telegráfico 1352 para DELBRASGEN. GATT. Reunião Ministerial. Secreto-Urgentíssimo. 18 de novembro de 1982. CDO/MRE.

82 Despacho Telegráfico 015 62350, op. cit.

83 Papel da Divisão de Política Comercial (DPC). O Brasil e o GATT. Abril de 1985, op. cit.

84 Informação para o Senhor Presidente da República. GATT. Reunião Ministerial das Partes Contratantes. Punta del Este: Instruçóes à Delegação Brasileira, op. cit.

85 Documento Final. [Sem autor]. Dezembro de 1986. PNB ONU GII 1983.03.00, Pasta XX, Doc. 22. CPDOC/FGV. 
representantes dos ministérios de Relaçóes Exteriores, Fazenda, Comunicações, da Secretaria Especial de Informática (SEI) e do Instituto Nacional de Propriedade Industrial (INPI), além do presidente da Associação Brasileira de Consultores de Engenharia. As conclusōes gerais do seminário eram contrárias às negociações de serviços no GATT. Segundo o relato obtido, "todos os representantes de setores presentes coincidiram em considerar contrária a seus interesses uma negociação internacional sobre serviços". Destacou-se também a "necessidade de proteção às empresas brasileiras no setor de serviços". Há menção de que o setor privado presente ao seminário "manifestou apreço pela atual postura do Governo brasileiro nos entendimentos que estão sob consideraçáo no GATT". No que tange ao setor de engenharia, concordou-se que a "política de defesa e de atribuição de preferência à consultoria e engenharia nacionais deveria ser preservada". ${ }^{86}$

Já em 1992, participaram da delegação brasileira em reuniōes de consulta bilateral sobre serviços no âmbito da Rodada Uruguai do GATT representantes da Câmara Brasileira da Indústria da Construção (CBIC), da Ordem dos Advogados do Brasil $(\mathrm{OAB} / \mathrm{SP})$ e do Serviço Brasileiro de Apoio às Micro e Pequenas Empresas (SEBRAE). ${ }^{87}$

Como se observa, houve alguns contatos entre o governo e o setor privado para tratar das negociaçóes sobre serviços no âmbito do GATT. Porém, esses contatos foram esporádicos. Ademais, da documentação disponível, depreende-se que os contatos ocorridos foram de iniciativa do Itamaraty, pois não há registros de manifestaçóes autônomas do setor privado. Mário Marconini confirmou, em entrevista ao autor, que, na época da Rodada Uruguai, o setor privado desconhecia as negociaçóes multilaterais em curso e, por isso, não houve mobilização e organizaçáo. Na mesma linha, Marcílio Marques Moreira, ex-embaixador do Brasil em Washington e ex-Ministro da Fazenda, conclui que "os grupos de interesse no Brasil, em geral, não têm uma dimensão de pressão internacional”. Ele afirma que, na Rodada Uruguai, "a presença de empresários era escassa" (Moreira 2001, 156). Com efeito, as informaçóes acima corroboram, em grande medida, as interpretaçóes que atribuem ao MRE um elevado grau de autonomia decisória face às preferências dos atores domésticos não governamentais.

\section{Conclusão}

Durante a Rodada Uruguai, a diplomacia brasileira manteve posição defensiva em relação ao tema do comércio de serviços. Da evidência disponível, conclui-se que não houve qualquer disputa interburocrática relevante no que toca às negociaçóes de serviços. Também conclui-se que os atores governamentais brasileiros possuíam visáo contrária à inclusão do tema na agenda do regime

86 Ibid.

87 Despacho Telegráfico 238. GATT. Rodada Uruguai. Serviços. Reunióes de consulta bilateral. Participantes brasileiros. Ostensivo-Urgente. 14 de fevereiro de 1992. CDO/MRE. 
multilateral de comércio, por acreditarem que a liberalizaçáo do setor ia de encontro ao interesse nacional. Essas preferências dos atores governamentais tinham origem, principalmente, em um conjunto de ideias que associava proteçáo do mercado interno a desenvolvimento econômico.

Quanto ao setor privado, dado o reduzido grau de abertura do setor de serviços ao comércio e investimento estrangeiro, poder-se-ia inferir que as preferências do setor eram contrárias a compromissos de abertura. De fato, a documentação disponível e as entrevistas realizadas confirmam essa interpretação. O mesmo poderia ser inferido quanto ao setor bancário; no entanto, não há registro de que tenha manifestado qualquer posição ao governo brasileiro.

Como se vê, as preferências dos atores governamentais e dos atores privados coincidiram no que concerne à posição que o país deveria adotar nas negociaçóes de serviços do GATT. Entretanto, não parece plausível a conclusão de que as preferências do setor privado constituem importante variável explicativa da posição negociadora brasileira. Os registros das preferências dos atores governamentais brasileiros pela oposição à negociação do tema são anteriores aos registros de qualquer contato relevante entre o governo e o setor privado, o que indica que essas preferências já eram previamente mantidas pela elite burocrática responsável pela condução da política externa econômica. As evidências documentais sobre as ideias dos atores governamentais sobre as relaçóes comerciais internacionais, somadas à reconhecida autonomia decisória gozada pelo Itamaraty, indicam que, independentemente da manifestação de preferências por parte do setor privado, a diplomacia brasileira teria defendido a mesma posição que de fato defendeu.

Não se pretende aqui concluir que as preferências do setor privado tenham sido irrelevantes na definição da posição brasileira. No entanto, a evidência disponível indica que seu valor explicativo é baixo. As preferências do setor privado parecem ter tido mais bem uma função de respaldo da posição adotada pela diplomacia brasileira.

\section{Referências bibliográficas}

ABREU, Marcelo de Paiva. O Brasil e o GATT: 1947-1990. In: ALBUQUERQUE, José Augusto Guilhon (org.). Sessenta Anos de Política Externa Brasileira (1930-1990), Volume 2: Diplomacia para o Desenvolvimento. São Paulo: Programa de Relaçôes Internacionais-USP/ Editora Cultura, 1996.

ABREU, Marcelo de Paiva. O Brasil na Rodada Uruguai do GATT: 1982-1993. In: FONSECA JÚNIOR, Gelson; CASTRO, Sergio Henrique N. de. (orgs.). Temas de Política Externa Brasileira II (Vol. 1). 2a ed. Brasília: FUNAG / Rio de Janeiro: Paz e Terra, 1997. p. 325-352.

ABREU, Marcelo de Paiva. O Brasil, o GATT e a OMC: História e Perspectivas. Política Externa, Vol. 9, No 4, 2001, p. 89-119.

ABREU, Marcelo de Paiva. Comércio Exterior: Interesses do Brasil. Rio de Janeiro: Elsevier, 2007. 
ALMEIDA, Paulo Roberto de. Formação da Diplomacia Econômica no Brasil: As Relaçôes Econômicas Internacionais no Império. 2a ed. São Paulo: Senac, 2005.

ARBILLA, José María. A diplomacia das idéias: a política da renovação conceitual da política externa na Argentina e no Brasil (1989-1994). Contexto Internacional, Vol. 2, № 2, 1997, p. 337-385.

BARTH, James R.; MARCHETTI, Juan A.; NOLLE, Daniel E.; Sawangngoenyuang, Wanvimol. Foreign Banking: Do Countries' WTO Commitments Match Actual Practices? WTO Staff Working Paper, ERSD-2006-11. World Trade Organization, Oct. 2006.

BOUZAS, Roberto (ed.). Domestic Determinants of National Trade Strategies: A Comparative Analysis of Mercosur Countries, Mexico and Chile. Paris: Chaire Mercosur de Sciences Po, 2006.

BOUZAS, Roberto; SOLTZ, Hernán. Argentina and GATS: A Study on the Domestic Determinants of GATS Commitments. In: GALLAGHER, Peter; LOW, Patrick; STOLER, Andrew L. Managing the Challenges of WTO Participation: 45 Case Studies. Cambridge: Cambridge University Press, 2005.

CALDAS, Ricardo W. Brazil in the Uruguay Round of the GATT: The Evolution of Brazil's Position in the Uruguay Round, with Emphasis on the Issue of Services. Ashgate Publishing, 1998.

CASTELAN, Daniel Ricardo. A implementaçáo do consenso: Itamaraty, Ministério da Fazenda e a liberalização brasileira. Contexto Internacional, Vol. 32, No 2, 2010, p. 563-605.

CHEIBUB, Zairo. Diplomacia e construção institucional: o Itamaraty em uma perspectiva histórica. Dados, Vol. 28, No 1, 1985, p. 113-131.

CHEIBUB, Zairo. A Carreira Diplomática no Brasil: o Processo de Burocratização do Itamarati. Revista de Administração Pública, Vol. 23, No 2, 1989, p. 97-128.

CROOME, John. Reshaping the World Trading System: A History of the Uruguay Round. Kluwer Law International, 1998.

FARIA, Carlos Aurélio Pimenta de. Idéias, Conhecimento e Políticas Públicas: Um Inventário Sucinto das Principais Vertentes Analíticas Recentes. Revista Brasileira de Ciências Sociais, Vol. 18, No 51, 2003, p. 21-30.

FARIAS, Rogério de Souza. Transição Malograda de um Poder Emergente? A Participação Brasileira nas Negociaçôes Tarifárias da Rodada Tóquio. Revista Brasileira de Política Internacional, Vol. 51, No 2, 2008, p. 179-96.

FARIAS, Rogério de Souza. O Brasil e o GATT (1973-1993): Unidades Decisórias e Política Externa. Curitiba: Juruá Editora, 2009.

FARIAS, Rogério de Souza. Sowing the Seeds of Leadership: Brazil and the Agricultural Trade Negotiations of the Uruguay Round. Journal of World Trade, Vol. 44, No 3, 2010, p. 661-85.

FARIAS, Rogério de Souza. Brazil and the Origins of the Multilateral Trading System. The International History Review. No prelo. doi: 10.1080/07075332.2014.897248.

HOEKMAN, Bernard M. Developing Countries and the Uruguay Round Negotiations on Services. CEPR Discussion Paper, No 822, 1993.

HOEKMAN, Bernard M. Tentative First Steps: an Assessment of the Uruguay Round Agreement on Services. World Bank Policy Research Working Paper, No 1455, 1995. 
MARCONINI, Mário. OMC, Acordos Regionais e o Comércio de Serviços: Normativa Internacional e Interesse Brasileiro. São Paulo: Aduaneiras, 2003.

MARZAGÃO, Thiago Veiga. Lobby e Protecionismo no Brasil Contemporâneo. Revista Brasileira de Economia, Vol. 62, No 3, 2008, p. 263-278.

MATTOO, Aaditya. Financial Services and the World Trade Organization: Liberalization Commitments of the Developing and Transition Economies. Policy Research Working Paper, No 2184. Washington, D.C.: The World Bank, Sept. 1999.

MATTOO, Aaditya (ed.). Brazil's Services Trade and International Trade Negotiations. In: World Bank. Brazil: Trade Policies to Improve Efficiency, Increase Growth and Reduce Poverty, 2004. p. 179-321.

MELLO, Flavia de Campos. O Brasil e o GATT: Análise da Posição Brasileira nas Negociaçóes Comerciais Multilaterais. 1992. Dissertação (Mestrado em Relaçôes Internacionais)-Pontifícia Universidade Católica do Rio de Janeiro, Rio de Janeiro, 1992.

PINHEIRO, A.C.; ALMEIDA, G. Padrōes Setoriais da Proteção na Economia Brasileira. Texto para Discussão, n. 355, IPEA, 1994.

PREEG, Ernest H. Traders in a Brave New World: The Uruguay Round and the Future of the International Trading System. Chicago: The University of Chicago Press, 1995.

CARVALHO, Maria Izabel Valladão de. O Itamarati, os Empresários e a Política Exterior do Brasil. Meridiano 47, No 7, p. 11-13, 2001.

CARVALHO, Maria Izabel Valladão de. Estruturas Domésticas e Grupos de Interesse: A Formação da Posição Brasileira para Seattle. Contexto Internacional, Vol. 25, No 2, 2003, p. 363-401.

MANCUSO, Wagner Pralon; OLIVEIRA, Amâncio Jorge de. Abertura Econômica, Empresariado e Política: Os Planos Doméstico e Internacional. Lua Nova: Revista de Cultura e Politica, Vol. 69, 2006, p. 147-172.

OLIVEIRA, Amâncio Jorge de; PFEIFER, Alberto. O Empresariado e a Política Exterior do Brasil. In: ALTEMANI, Henrique; LESSA, Antônio Carlos (orgs.). Relaçôes Internacionais do Brasil: Temas e Agendas, Vol. 2. São Paulo: Saraiva, 2006. p. 389-427.

OLIVEIRA JÚNIOR, Márcio de. Uma Análise da Liberalização do Comércio Internacional de Serviços no Mercosul. Texto para Discussão, No 727, IPEA, 2000.

PIO, Carlos. A Estabilização Heterodoxa no Brasil: Idéias e Redes Políticas. Revista Brasileira de Ciências Sociais, Vol. 16, No 46, 2001, p. 31-54.

SPEKTOR, Matias. Ideias de Ativismo Regional: A Transformação das Leituras Brasileiras da Região. Revista Brasileira de Política Internacional, Vol. 53, No 1, 2010, p. 25-44.

VEIGA, Pedro da Motta. Formulação de Políticas Comerciais no Brasil: Mudança do Padrão de Relacionamento entre o Estado e a Sociedade Civil. Revista Brasileira de Comércio Exterior, No 86, 2006.

\section{Fontes primárias}

Arquivo Paulo Nogueira Batista - PNB, CPDOC/FGV.

Arquivo Marcílio Marques Moreira - MMM, CPDOC/FGV.

Arquivo Histórico do Ministério das Relaçôes Exteriores, Brasília - CDO/MRE. 
Documentos do GATT - GATT Digital Library. Disponível em: http://gatt.stanford.edu. Acesso em: 25 fev. 2008.

\section{Entrevistas}

Embaixador José Alfredo Graça Lima (17 de abril de 2008). Coordenador das negociaçóes do Brasil na Rodada Uruguai, Missão Permanente do Brasil em Genebra, 1986-1988. Chefe da Divisão de Política Comercial (DPC/MRE), 1988-1991.

Ministro Luís Antonio Balduino Carneiro (25 de abril de 2008). Encarregado das negociaçóes sobre o comércio de serviços na Rodada Uruguai, Missão Permanente do Brasil em Genebra, então Segundo Secretário, 1991-1994.

Mário Marconini (2 de julho de 2007). Economista do GATT/OMC, 1988-1996. Subsecretário de Assuntos Internacionais, Ministério da Fazenda, 1996-1998. Secretário de Comércio Exterior, Ministério do Desenvolvimento, 1999. Atual Presidente do Conselho de Relaçóes Internacionais da Fecomércio-SP e coordenador do "Diálogo Serviços".

Representante do setor de engenharia e construçáo [anônimo] (9 de abril de 2008). Encarregado de negociaçóes comerciais em entidades de representação do setor nas rodadas Uruguai e Doha.

Recebido em 28 de janeiro de 2015

Aceito em 13 de março de 2015

\section{Resumo}

Por que o Brasil tem tradicionalmente adotado postura defensiva em negociações multilaterais sobre o comércio de serviços? São três as principais categorias explicativas comumente usadas para entender os determinantes domésticos da diplomacia econômica: interesses, instituições e ideias. Neste estudo, avalio o papel dessas variáveis na determinação da posição brasileira nas negociações de serviços da Rodada Uruguai. O estudo de caso apresentado se vale de fontes primárias e entrevistas para reconstituir a posição negociadora do país ao longo da rodada, identificar as preferências dos atores governamentais e não governamentais relevantes e apontar os mecanismos e instâncias de interação entre governo e setor privado.

Palavras-chave: diplomacia comercial; GATT; Rodada Uruguai; serviços.

\section{Abstract}

Why has Brazil traditionally adopted a defensive position in multilateral negotiations on trade in services? Three explanatory factors are typically used for understanding the domestic determinants of economic diplomacy: interests, institutions, and ideas. In this study, I assess the role of these variables in determining the Brazilian stance in the negotiations on trade in services in the Uruguay Round. I use archival evidence and interviews in a case study designed to recover the country's negotiating position throughout the round of negotiations, identify the preferences of relevant government and private actors, and reveal the mechanisms and loci of government-business interaction.

Keywords: trade diplomacy; GATT; Uruguay Round; services. 